\title{
Relative Hypoleptinemia in Poorly Controlled Patients with Type 1 Diabetes
}

Authors

Affiliation

\section{C. Amato, A. Ciresi, P. Richiusa, A. Criscimanna, L. Allotta, A. Mattina, A. Galluzzo, C. Giordano}

Endocrinology \& Metabolism Section, Università degli Studi di Palermo, Department of Experimental Oncology and Clinical Applications (DOSAC), Palermo, Italy

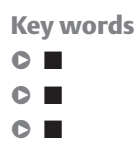

received 4.10.2006 accepted 22.1.2007

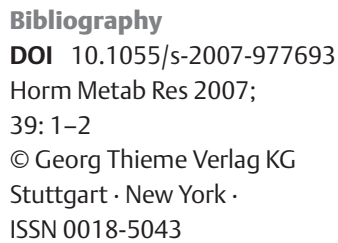

Correspondence

Prof. C. Giordano, MD

Endocrinology \& Metabolism Section

Università di Palermo

Department of Experimental Oncology and Clinical Applications (DOSAC)

Piazza delle Cliniche 2

90127 Palermo

Tel.: + 39/091/655 2109

Fax: +39/091/6552123

cgiordan@unipa.it

\section{Abstract \\ $\nabla$ \\ $\mathbf{\square} \mathbf{\square}$}

\section{Introduction}

\section{$\nabla$}

Insulin sensitivity is strictly related to body fat mass. Several studies in type 2 diabetes (T2DM) demonstrated that insulin regulates leptin (Lep) per se, regardless of adiposity [1,2]. On the contrary, plasma adiponectin (Apn), another molecule specifically secreted from adipocytes, is negatively correlated with insulin resistance and body mass index (BMI) $[3,4]$. Unlike the HOMAIR, an index of insulin resistance, the adiponectin/ leptin ratio $(A / L$ ratio) is not influenced by fasting glucose plasma levels and could be considered a sensitive and reliable marker of insulin resistance in T2DM. Type 1 diabetes mellitus (T1DM) is an organ-specific autoimmune disease resulting from the T-cell mediated destruction of pancreatic $\beta$-cells, though glycemic control is also related to reduction in insulin sensitivity. Although it is well known that adipocytokines, principally Lep, may influence T-cell function $[5,6]$, their role in insulin sensitivity has not been sufficiently investigated in Type 1 diabetes.

\section{Material and Methods}

The aim of this prospective study was to evaluate whether insulin sensitivity could influence glycemic control in patients with T1DM after 5 years from the onset. The patients were classified, in accordance to ADA criteria, as T1DM because of acute onset of symptoms, DKA and positive pancreatic $\beta$-cell auto-antibodies (anti-GAD and/or anti-IA2). We studied 25 consecutive (20 males, 5 females) non-obese (BMI $23.66 \pm 3.49 \mathrm{Kg} / \mathrm{m}^{2}$; range 19-29.5) T1DM subjects, aged $22 \pm 9.21$ years. We excluded patients with obesity (class IIII) in order to eliminate those who had clear insulin resistance associated to T1DM. All subjects followed a balanced nutritional scheme and kept a diary to quantify compliance to the diet program (number of days of free food intake). After three months we assessed insulin resistance by evaluating clinical signs and symptoms (acanthosis nigricans, waist circumference, BMI, blood pressure), biochemical parameters (HbA1c, lipids, uricemia), adipocytokine levels (Apn, Lep and A/L ratio) and endothelial dysfunction markers (microalbuminuria and PCR). Residual $\beta$-cell function was determined by measuring urinary (UCP) and serum C-peptide levels evaluation before and after a glucagon test $\left(0^{\prime}\right.$ and $\left.6^{\prime}\right)$. The Institutional ethics committee approved the study and all participants signed informed consent. Data are presented as mean $\pm S D$. The Mann-Whitney U test was used to compare groups. A linear logistic regression model was applied to determine the relationship between dependent (HbA1c) and independent variables (IR, Waist, BMI, CPU, 0' and 6' C-peptide, Adp, Lep, $\mathrm{A} / \mathrm{L}$ ratio, number of days of non-regular diet).

\section{Results \\ $\nabla$}

Patients were divided in two groups based on BMI: BMI $<26 \mathrm{~kg} / \mathrm{m}^{2}$ (18/25, Group A) and BMI $>26 \mathrm{~kg} / \mathrm{m}^{2}$ (7/25, Group B). Lep values were significantly higher $(9.4 \pm 6.4 \mathrm{ng} / \mathrm{ml} \mathrm{vs.} 3.3 \pm 2.9 \mathrm{ng} / \mathrm{ml}$; $\mathrm{p}=0.005)$ and $\mathrm{A} / \mathrm{L}$ ratio significantly lower $(2.4 \pm 1$ vs. 18.6 $\pm 25.9 ; p<0,001)$ in group $B$. No significant differences were found for other parameters examined, suggesting that glycemic control and 
Table 1 Clinical and metabolic parameters in Type 1 diabetic patients with $<26 \mathrm{Kg} / \mathrm{m}^{2}(\mathrm{Group} \mathrm{A})$ and $>26 \mathrm{Kg} / \mathrm{m}^{2}$ (Group B) BMI

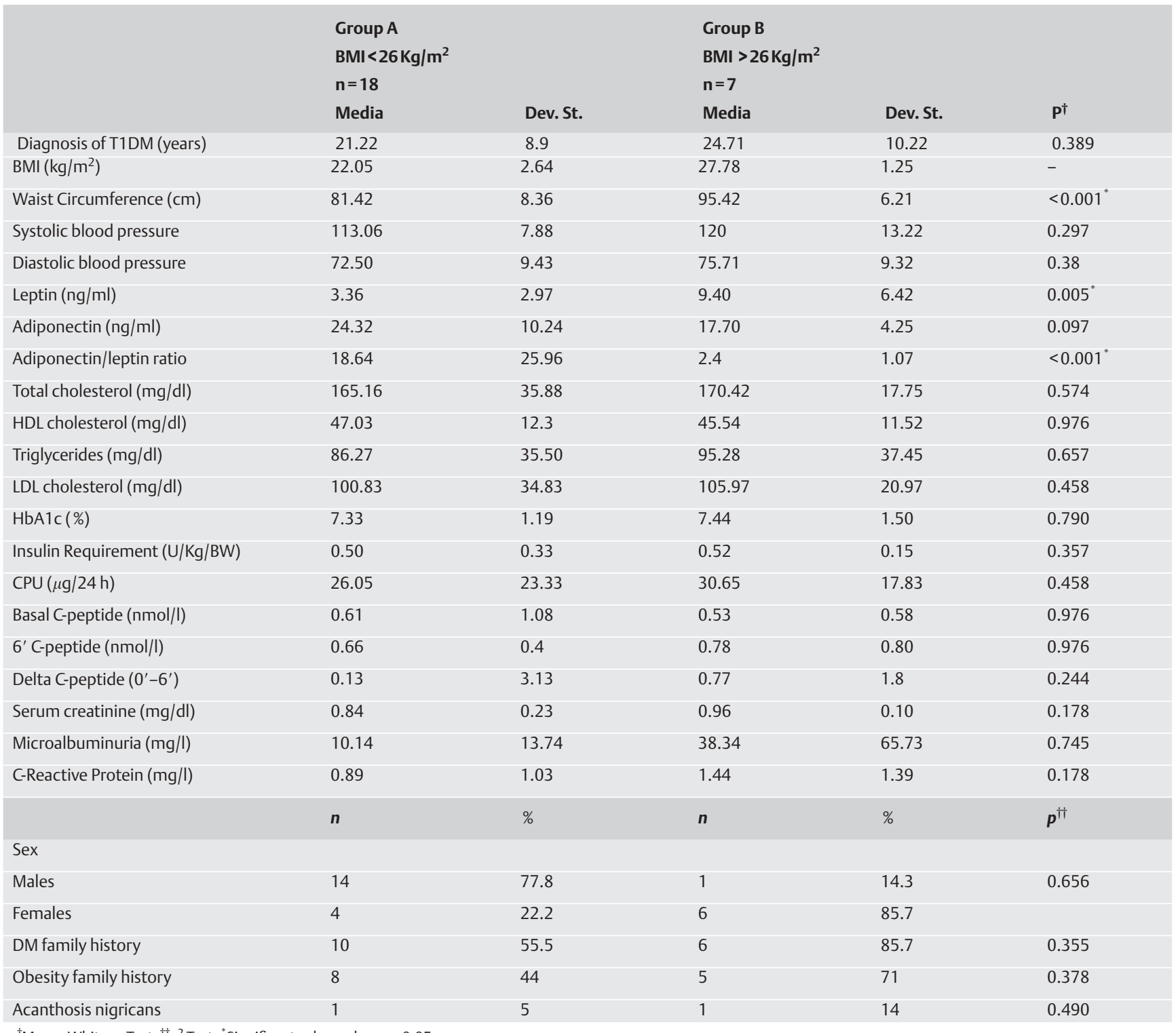

${ }^{\dagger}$ Mann-Whitney Test; ${ }^{\dagger} \chi^{2}$ Test; ${ }^{*}$ Significant values when $\mathrm{p}<0.05$

residual $\beta$-cell function did not differ in normal weight patients (group A) and overweight patients (group B) (Table 1). Using a multiple linear logistic regression model to evaluate which of the independent variables could influence $\mathrm{HbA1c}$, we found that high HbA1c values correlated with increased BMI $\beta=0.73 ; \mathrm{p}=0.034)$, IR $(\beta=0.74 ; \mathrm{p}=0.001)$, number of days of non-regular diet $(\beta=0.40$; $\mathrm{p}=0.015)$ and reduced Lep levels $(\beta=-0.71 ; \mathrm{p}=0.004) . \mathrm{A} / \mathrm{L}$ ratio was significantly lower in group B (overweight), as Apn levels (related to insulin resistance) did not differ in the two groups, and only Lep values (obviously higher in group B) markedly influenced $\mathrm{A} / \mathrm{L}$ ratio. Thus it is not possible to assert that these patients are less insulin sensible only on the basis of A/L ratio.

\section{Conclusions \\ $\nabla$}

In conclusion, we have found an association between poor compliance to diet and elevated HbA1c with relative hypoleptinemia in nonobese patients with T1DM, similar to patients affected by the metabolic syndrome [7]. Hypoleptinemia could accelerate lipogenesis and reduce FFA oxidation in muscle and liver, thus decreasing insulin sensitivity in these tissues. From our study, we hypothesize that the transient lipotoxicity is able to influence glycemic control and HbA1c values in Type 1 diabetes.

\section{References}

1 Mohamed-Ali V, Pinkney JH, Panahloo A, Goodrick S, Coppack SW, Yudkin JS. Diabetic Med 1997; 14: 376-380

2 Widjaja A, Stratton IM, Horn R, Holman RR, Turner R, Brabant G. J Clin Endocrinol Metab 1997; 82: 654-657

3 Hotta K, Funahashi T, Arita Y, Takahashi M, Matsuda M, Okamoto $Y$, Iwahashi H, Kuriyama H, Ouchi N, Maeda K, Nishida M, Kihara S, Sakai $N$, Nakajima T, Hasegawa K, Muraguchi M, Ohmoto Y, Nakamura T, Yamashita S, Hanafusa T, Matsuzawa Y. Arterioscler Thromb Vasc Biol 2000; 20: 1595-1599

4 Inoue M, Maehata E, Yano M, Taniyama M, Suzuki S. Metabolism 2005; 54: $281-286$

5 Matarese G, Sanna V, Lechler RI, Sarvetnick N, Fontana S, Zappacosta S, La Cava A. Diabetes 2002; 51: 1356-1361

6 Imagawa A, Funahashi T, Nakamura T, Moriwaki M, Tanaka S, Nishizawa H, Sayama K, Uno S, Iwahashi H, Yamagata K, Miyagawa J, Matsuzawa Y. Diabetes Care 2002; 25: 1665-1666

7 Unger RH. Nature. Endocrinology 2003; 144: 5159-5165 